\title{
REINVENTING THE FAÇADE: NON-OBVIOUS SYMMETRIES IN ARCHITECTURAL DESIGN AND URBAN PLANNING
}

\author{
Vilmos Katona ${ }^{*}$ \\ * Institute of Architecture, Faculty of Engineering and Information Technology, University of Pécs, 2 \\ Boszorkány út, Pécs 7624, Hungary. \\ E-mail: katwilat@gmail.com; katona.vilmos@mik.pte.hu \\ ORCID: $\underline{0000-0002-0299-2897}$
}

In our thematic issue, Symmetry welcomed multidisciplinary articles on the role of nonobvious symmetries in architectural design and city planning, with special regard to urban façades, social participation, and the concept of beauty in tectonic culture.

Architectural theories of the past decades have showcased a multiverse of possibilities and creative approaches, all the while blurring the boundaries between schools and disciplines. We have witnessed the competing theories of tectonic culture versus deconstructivism, or critical regionalism versus the 'manager avant-garde'; in the midst of this archipelago of competing theories lies a theoretical terra incognita. These vague territories, however, allow us to exchange information, conceptualize new methods and make new policies. Today's peripheries may form the centres of the future-not by merging into one solid system, but by a process that may result in the rise of open, yet well-recognizable architectural characters.

The need for communication has increased the importance of façades from the individual house to the greater urban megaforms and interiors. Façades carry messages and collective memories on different scales, not only allowing us to construe our built environment, but even inducing urban rituals. Façades are often regarded with a sort of benign neglect, and considered secondary to general plans, spatial structures and syntax 
analyses, though a thorough survey on architectural theory would show that façades as autonomous entities have their own history. From Vitruvius to Andrea Palladio, from Palladio to Gottfried Semper, and from Semper to Vincent Scully-not to mention philosophers like Friedrich Nietzsche, Martin Heidegger, Gilles Deleuze or Jean Baudrillard—several renowned thinkers have given us opportunities to better understand our cities, starting from their 'skin'. It is time to read these theories again, to develop a new practical knowledge, and to facilitate contemporary patterns of social interaction and cultural sustainability.

The fundaments of the tectonic culture are, both philologically and practically, derivable from two equal principles: the structure and the building's 'membrane'. However, the twofold nature of the tectonics is hardly represented in contemporary arguments, and the 'architectural phenomenologists' still prefer the dominance of structure over the buildings' meaningful 'dress'. Meanwhile, studying the urban gaps of Europe, the United States and the Third World, it may be noticed that there is a certain need for the reenactment of aesthetics and social participation in architecture to overwrite 'terrain vague'. It has been revealed that the nexus between people and their built environment heavily depends on the use of certain non-obvious types of symmetries that generate visual patterns. By building new stages of urbanism, our experiences may converge into a comprehensive understanding of urban façades, and our tectonic culture in general. By deciphering aesthetics through mathematics, we could also achieve long-term models of participatory city rehabilitations, the reuse of public space and social revitalization. 